Motrivivência v. 27 , n. 45 , p. $280-297$, setembro/2015

http://dx.doi.org/10.5007/2175-8042.2015v27n45p280

\title{
I MANDATO GOVERNO LULA DA SILVA-PT (2003-2006) E AS POLÍTICAS DE ESPORTES: aprofundando o projeto neoliberal
}

\author{
Marcelo Paula Melo' \\ Edson Marcelo Hungaro² \\ Pedro Fernando Athaude ${ }^{3}$
}

\section{RESUMO}

O objetivo desse artigo é debater as ações do Ministério do Esporte no I Mandato do Governo Lula da Silva/PT (2003-2006). Esse recorte temporal justifica-se por esse mandato ter sido considerado como momento de disputas internas acerca dos rumos do governo e com expectativas de que o PT no poder poderia representar uma perspectiva de enfrentamento da lógica burguesa brasileira. Mostraremos que essas expectativas não se concretizaram e que a adesão programática ao projeto neoliberal esteve presente nos programas e pronunciamentos de seus dirigentes. A incorporação de ações fundadas na responsabilidade social, da defesa da atuação de organismos na sociedade civil via políticas de parcerias e defendendo a isenção fiscal para repasses de recursos públicos para tais entidades, a proposta de utilização de trabalho voluntário autoriza a tais afirmações.

Palavras-chave: Políticas; Esportes, Lula da Silva-PT; Neoliberalismo

1 Doutor em Serviço Social. Docente da Escola de Educação Física e Desportos UFRJ. Rio de Janeiro/RJ, Brasil. E-mail: marcelaomelo@gmail.com

2 Doutor em Educação Física. Docente da UNB. Brasília/Distrito Federal, Brasil. E-mail: mhungaro@unb.br

3 Doutor em Política Social. Docente da UNB, Brasília/Distrito Federal, Brasil. E-mail: pedroavalone@gmail.com 


\section{INTRODUÇÃO}

A eleição de Luiz Inácio Lula da Silva e do PT para Presidência da República representou tempos de grandes expectativas na sociedade brasileira. Pela primeira vez um partido forjado nas lutas políticas dos trabalhadores, com clara identificação com setores populares e histórico de militância política de esquerda, conseguia ascender eleitoralmente ao cargo mais alto do país, tendo como slogan a ideia de que "a esperança venceu o medo". Contudo, tanto Lula da Silva como o PT que chegaram à vitória pouco guardam relações com o Partido que representou, nos anos 1980 e início dos 1990, um aglutinador das demandas significativas da classe trabalhadora, das organizações sindicais, das comunidades eclesiásticas de base e de movimentos populares. A paulatina transformação sofrida ao longo de sua constituição foi apontando para distância das demandas da classe que o constituiu em prol de estratégias que permitissem o êxito eleitoral. Segundo Coutinho (2006), o PT foi responsável pela maior operação transformista da história política nacional.

As expectativas de mudança também se fizeram presentes no campo da Educação Física e esporte. Os setores mais progressistas ansiavam por ações que buscassem minimamente contrarrestar o histórico da área de abordagens superficiais sobre papel do esporte e lazer como direitos sociais, bem como de favorecimento ao esporte espetáculo, especialmente devido a seu potencial ideopolítico e econômico. Partindo do entendimento de que a atuação do Ministério do Esporte (ME) não pretendeu (ou conseguiu, caso fosse o projeto) enfrentar os determinantes do projeto histórico dominante, esse artigo busca debater como no I Mandato do Governo Lula da Silva/PT as ações do ME fundamentam-se nos pressupostos da orientação dominante (neoliberal). O recorte temporal adotado justifica-se pelo fato de que o mandato inicial pode ser visto como momento de disputas internas acerca dos rumos do governo e com expectativas de que o PT no poder poderia representar uma perspectiva de enfrentamento da lógica burguesa brasileira, com tudo que tem de antipopular. Para tal, foram analisados documentos do Ministério do Esporte no referido período. Esses documentos são de diversas naturezas; textos explicativos de programas implementados (BRASIL. MINISTÉRIO DO ESPORTE, 2004b); textos que explicitavam "A Política Nacional de Esporte" (BRASIL. MINISTÉRIO DO ESPORTE, 2003, 2005) e documentos acerca das Conferências Nacionais de Esporte (BRASIL. MINISTÉRIO DO ESPORTE, 2004a, 2006a, 2006b).

Num momento em que o suposto fim do neoliberalismo é cantado e decantado aos qua tro ventos, faz-se necessário discutir não somente sua permanência, mas seu aprofundamento em nível mundial e no Brasil, com nova roupagem. Como alerta David Harvey (2008) só é possível considerar que estamos diante do fim do neoliberalismo caso tenhamos uma visão extremamente pobre acerca do que venha ser tal fenômeno. É preciso tomar o neoliberalismo como um projeto político do conjunto da classe burguesa, dirigida por sua fração financeira, passível não somente de restaurar o poder dessa classe, mas garantir a hegemonia frente às classes dominadas, e convencer ou agrupar outras frações da classe dominante, mediante o processo 
de mundialização e financeirização da economia. Buscando explicar as faces com que o capitalismo neoliberal buscou se apresentar, essa nova fase do capitalismo é tomada como:

uma teoria das práticas político-econômicas que propõe que o bem-estar humano só pode ser melhor promovido liberando-se as liberdades e capacidade empreendedoras individuais no âmbito de uma estrutura institucional caracterizada por sólidos direitos a propriedade privada, livres mercados e livre comércio (HARVEY, 2008, p. 12).

A defesa da manutenção do projeto neoliberal nessa conjuntura deve-se ao fato da aceitação e não questionamento de aspectos centrais desse projeto. Questões como: (i) privatização de empresas estatais, estradas e outros equipamentos estatais; (ii) execução de políticas sociais por meio das ditas parceiras público privadas com organizações na sociedade civil; (iii) manutenção das bases do projeto da finança mundializada dentre outros elementos debatidos mais a frente autorizam a fazer tal afirmação.

\section{PT e a configuração de uma esquerda para o capital}

A trajetória do PT é elucidativa dos dilemas enfrentados pela esquerda no Brasil e no mundo. Saudado como maior partido de esquerda da América Latina, ganhou destaque nacional e internacional quando nas primeiras eleições nacionais para presidente depois da ditadura militar quase chegou à vitória em 1989 no segundo turno. Mesmo com essa derrota, o PT continuou angariando algumas vitórias nas eleições regionais, além de eleger uma pequena, mas combativa bancada parlamentar. Mais do que isso, sua atuação política representava o que Fontes (2005) chamou de qualificação da política, visto que naquele momento, a atuação do PT como um todo, e de seus filiados, se caracterizava por uma lógica que se contrapunha a visão corrente da política no Brasil. O PT desempenhava também uma função pedagógica que colocava a organização e educação política do conjunto da classe trabalhadora à frente de eventuais vitórias eleitorais.

É comum a afirmação de que o PT teria mudado com a chegada ao Governo Federal. Todavia, nota-se que tais modificações programáticas e de concepções de mundo já se manifestavam anteriormente. Nas eleições de 2002, essa nova configuração foi representada por uma série de mudanças nas estratégias eleitorais utilizadas pelo PT. Como vice-presidente foi escolhido o então senador José Alencar, (PL-MG, atualmente PR) importante industrial do setor têxtil e vice-presidente da Confederação Nacional das Indústrias (CNI), abrindo portas para aceitação da burguesia industrial brasileira - setor majoritariamente hostil a Lula da Silva e ao PT - e acalmando o empresariado que ameaça retirar seus investimentos no mercado interno. Tanto que, diversas vezes, ao se referir sobre sua chapa com Alencar, Lula da Silva afirmava ser a prova viva da possibilidade de união entre capital e trabalho. Grosso modo, tratava-se de uma aliança pautada no pragmatismo que hegemonizava a atuação petista.

Como aponta Francisco de Oliveira (2006) era preciso "despetizar" Lula da Silva, ou seja, eliminar qualquer evidência que o vinculasse ao histórico candidato de um partido de esquerda socialista. Como ficou conhecido naquele momento, o 
"Lulinha, paz e amor" foi a espetacularização do candidato que se apresentava como representante dos trabalhadores. Cavalcanti (2003) explicita que o marketing político em torno de Lula tentava trabalhar suas características pessoais para promover uma operação de transfiguração política. Segundo o autor, tratava-se de agregar valor ao seu perfil administrativo e reforçar sua imagem como gestor. Nesse sentido, em determinado momento valorizava-se o perfil presidencial, colocando-o como homem capaz de julgar, avaliar situações e, por isso, ser confiável como presidente. Ao mesmo tempo, reforçava-se a imagem de gestor capacitado para tomar as decisões de governo mais acertadas. Ao fim e ao cabo, o objetivo publicitário era transferir a imagem serena adotada durante a campanha para a figura de presidente da pacificação, o que neutralizaria a tática da oposição de semear o medo entre os eleitores e, posteriormente, acentuaria a conduta de presidente apto para construir politicamente.

Um dos momentos mais emblemáticos do transformismo de Lula da Silva e do PT foi a apresentação da chamada "Carta ao Povo Brasileiro". Este documento foi apresentado à nação em junho de 2002, no momento em que circulavam na grande mídia notícias de que a possibilidade de vitória do candidato do PT estaria deixando os "mercados nervosos" ou instáveis. Esse "nervosismo do mercado" se manifestaria com a alta do dólar, a desvalorização dos títulos brasileiros no mercado externo, o descontrole inflacionário e o aumento do risco país.

Desde a apresentação do documento ficou claro que seu objetivo foi tranquilizar a fração financeira da burguesia nacional e, sobretudo internacional, de que as bases do projeto de financeirização da economia estariam garantidas com uma eventual vitória do candidato do PT. Isso é explicitado na garantia de que eventuais mudanças no país se darão de forma "cuidadosa", sem espaços para aventuras, uma vez que será

... preciso compreender que a margem de manobra da política econômica no curto prazo é pequena (p. 2) [sendo precedidas pelas] ... reformas estruturais que de fato democratizem e modernizem o país, como reforma previdenciária, a reforma trabalhista (LULA DA SILVA, 2002, p. 1).

A garantia de que haveria o respeito aos contratos e obrigações do país - para usar expressões presentes na Carta - foi dada com a nomeação de Henrique Meireles para a Presidência do Banco Central, um ex-funcionário do Banco de Boston, que havia sido eleito Deputado Federal pelo PSDB de Goiás. A partir daí, diversas frações burguesas tiveram a certeza de que não havia razões para temer o Governo Lula e do PT, que finalmente chegaram ao Palácio de Planalto com a expressiva votação no segundo turno de 52 milhões de votos.

Oliveira (2006) traz uma reflexão relevante acerca dessa chegada de Lula da Silva e do PT ao poder central em 2002. Segundo o autor:

... o paradoxo da eleição de Lula é que ele chega ao governo quando sua classe mergulha numa avassaladora desorganização. A inespecificidade de sua eleição, o "Lulinha Paz e Amor", é contraditória e, perversamente, o sinal da desimportância de sua legendária base classista. Talvez só ele e seu marqueteiro tenham percebido que era possível dar essa guinada exatamente porque o poder de veto de sua antiga 
base de trabalhadores havia se reduzido a quase nada. Mas o carisma criado pelo seu pertencimento a um movimento operário que havia jogado a ditadura às cordas e havia contribuído para a redemocratização do país ainda permanecia, e foi seu cacife para as eleições (OLIVEIRA, 2006, p. 37).

Aproveitando-se do cenário de turbulência econômica, resquício da conturbada disputa eleitoral, e de uma suposta ameaça de bancarrota financeira, o Governo Lula da Silva/PT teve seu início em 2003 mantendo as diretrizes da política econômica e fiscal do governo anterior. A surpreendente elevação da taxa básica de juros, que chegou a atingir $26,5 \%$ ao ano, o aumento voluntário do superávit primário de $3,75 \%$ para $4,25 \%$ do PIB e a Reforma da Previdência Social dos servidores públicos deram mostras suficientes de que o processo de finança mundializada estaria garantido no Governo Lula da Silva, conforme indica Leda Paulani (2006).

A Reforma da Previdência no Governo Lula da Silva, uma de suas primeiras medidas ao tomar posse em 2003, incidiu nos servidores públicos. Considerando o potencial regressivo representado por esse projeto e o fato de serem os servidores públicos uma das categorias de trabalhadores com forte identificação política com o PT, a referida reforma foi um sinal de quais interesses de classe seriam contemplados, segundo as indicações e análises de Paulani (2006) e Behring \& Boschetti (2007). A busca por diminuição dos gastos nesse campo guiou a reforma da Previdência Social.

Logo após as eleições em 2002, Lula da Silva defendeu que a preocupação central de seu governo seria o combate à fome. Para isso, criou o programa FOME ZERO, que tentou se tornar um símbolo do governo. Após problemas de várias naturezas e com parcos resultados, esse programa passa a perder espaço para o chamado BOLSA FAMÍLIA, uma unificação de outros programas sociais existentes até então como Bolsa Escola, Bolsa Alimentação, Cartão Alimentação e Auxílio gás.

Como afirmam Rosa Marques e Áquila Mendes (2006) os programas de transferência de renda começam a lançar novas bases de apoio político direcionados aos setores mais empobrecidos e menos organizados politicamente da população. Em dezembro de 2004 este programa estava implantado em 99,5\% dos municípios, com uma população atingida de 6.571.182 famílias. No ano de 2010, o Programa Bolsa Família atingiu mais de 12,5 milhões de famílias, com um investimento aproximado de R\$13 bilhões ${ }^{4}$.

Com uma parcela mínima do PIB, os programas de renda mínima atingem aproximadamente 50 milhões de brasileiros que estavam na mais estreita miséria e indigência. Segundo Fagnani (2012), programas focalizados nas camadas mais empobrecidas têm como objetivo final a reforma do Estado e o ajuste fiscal, tendo em vista

4 Segundo informações do Ministério do Desenvolvimento Social. Disponível em: <http://www.mds.gov.br/ bolsafamilia >. Acesso em: 15 jun. 2011. 
que programas dessa natureza são baratos em termos de gastos como proporção do PIB. Essa compreensão orienta o objetivo tácito na tentativa dos organismos internacionais de alçar o Programa Bolsa Família (PBF) - implantado pelo Governo Lula - em um case internacional de sucesso. A própria OIT evidencia os fundamentos que baseiam sua conclusão ao afirmar que a cobertura de 47 milhões de pessoas foi possível "com um nível de gastos de $0,4 \%$ do PIB, o que representa $1,8 \%$ do gasto do Governo Federal" (ClCHON, BEHRENDT, WOSDAK, 2011. p. 10).

Se inegavelmente os setores mais empobrecidos estão em situação menos drástica, também é possível defender que isso não foi barreira para aumento da concentração de renda e da desigualdade. De acordo com Pereira-Pereira (2012), a política social de Lula é marcada por uma situação paradoxal, que, ao fim e ao cabo, coloca em xeque a pretensão neodesenvolvimentista do referido governo. Para Pereira-Pereira, é correto reconhecer que houve melhoria das condições sociais de muitos brasileiros, no entanto, simultaneamente, é notável a acentuada melhora da remuneração do capital financeiro, industrial e do agronegócio que operam no país.

Ou seja, foi no governo Lula que o enfrentamento da pobreza absoluta teve a maior visibilidade política de sua endêmica existência, mas, paradoxalmente, isso foi acompanhado da garantia "de altos lucros, comparáveis com os mais altos da história recente do Brasil" (Antunes, 2011, p. 131) a diversas frações do capital. Portanto, se a pobreza absoluta ou extrema diminuiu a desigualdade, não sofreu decréscimos; e se a pobreza absoluta ou extrema preocupou o governo, o combate à concentração de riqueza não foi alvo dessa preocupação. E o país continua injusto (PEREIRA-PEREIRA, 2012, p. 746).

Um dos eixos políticos alardeados pelo Governo Lula da Silva e do PT como vitórias suas seria a nova posição do país na divisão internacional do trabalho e um reposicionamento político na relação com outros países capitalistas centrais e periféricos e com alguns organismos internacionais. Tanto a inserção do Brasil dentre as economias mais ricas, como uma suposta posição mais incisiva nos fóruns internacionais teriam elevado o patamar do país no conjunto das relações internacionais.

Cabe analisar o que efetivamente representou essa mudança de patamar. Tendo aceitado a condição de sócio menor da divisão internacional do trabalho, a dita integração do Brasil ao mercado mundial se dá via exportação de produtos agrícolas (commodities) e minerais ou de pequeno valor tecnológico. Essa ênfase na vocação exportadora, ainda que possa ter efeitos internos positivos no curto prazo, recoloca o tipo de dependência em face do exterior. A dinâmica de funcionamento da economia do país fica submetida à capacidade, ou melhor, a possibilidade de exportação e obtenção de superávits comerciais. Todavia, é necessário frisar que a obtenção de dados positivos na balança comercial foi favorecida dentro de uma conjuntura internacional favorável, na qual as commodities encontram-se valorizadas no mercado estrangeiro. Além disso, no caso brasileiro a melhoria deve-se, em larga escala, ao fortalecimento da parceria comercial com a China, que manteve aquecido o preço das commodities devido à intensa demanda do país asiático por esses produtos (FILGUEIRAS E GONÇALVES, 2007). 
Essa voracidade das exportações e a necessidade de saldos positivos na balança comercial guardam relação direta com a garantia de rentabilidade para a fração financeira internacional e nacional da burguesia que exploram os títulos da dívida pública brasileira. Assim, na atual divisão internacional do trabalho, o Brasil e também outros países da periferia do sistema capitalista - atuam como local de envio de lucros e dividendos para os países centrais, através da atuação de filiais de grandes empresas. As políticas de privatizações dos anos 1980 e 1990 - de acordo com cada formação social específica - desempenham um papel central nesse processo. Os processos de vulnerabilidade e subsunção dos países periféricos se acentuam, ainda que algumas frações de suas burguesias tenham obtido grandes lucros com esse processo.

É nesse quadro que se tornam elucidativas as palavras de Boito Júnior. (2005, p. 66)

... o governo Lula promoveu a ascensão da grande burguesia interna industrial e agrícola sem quebrar a hegemonia das finanças. Iniciou a sua política agressiva de exportação, centrada no agronegócio, nos recursos naturais e nos produtos industriais de baixa densidade tecnológica, e implementou as medidas cambiais, creditícias e outras necessárias para manter essa política. Tratou-se de uma vitória, porém parcial, da grande burguesia interna industrial e agrária. Essa fração burguesa permaneceu como força secundária no bloco no poder, uma vez que o Estado continuou priorizando os interesses do capital financeiro, mas o governo Lula ofereceu a ela uma posição bem mais confortável na economia nacional.

Outra expressão desse movimento transformista foi chamada por Eurelino
Coelho (2012) de uma "Esquerda para o capital", expressão que busca ilustrar a desqualificação da atuação política do PT ao chegar ao governo central. As alianças feitas em nome da dita governabilidade a partir de uma suposta ausência de alternativas implicou na reabilitação e aproximação com quadros históricos - individuais e coletivos - da burguesia por meio de partidos e entidades empresariais. Menos do que surpresa, tratou-se da confirmação de que eventuais antagonismos e projetos históricos dissidentes haviam ficado no passado.

\section{Políticas de esportes no I mandato Lula da Silva-PT (2003 -2006)}

As expectativas em torno de mudanças advindas da chegada de Lula da Silva e do PT ao Palácio do Planalto também incidiram em parte do campo (progressista) da Educação Física brasileira. A criação de um Ministério específico para o esporte - desvinculado de outras áreas em que possuísse ou não interface, como por exemplo, Educação, Cultura, Turismo e etc. - surgiu como um sinal de maior participação do Estado nas questões atinentes à política esportiva e, quiçá, como uma possibilidade de avanços na área.

Todavia, uma pasta ministerial recentemente criada, caracterizada pela escassez de infraestrutura física e pessoal, pela baixa visibilidade política e por uma dotação orçamentária inexpressiva, não despertou o interesse dos principais partidos políticos que compunham a base governista. Diante desse cenário, a direção do Ministério do Esporte foi entregue ao PCdoB, que escolheu, entre seus quadros, Agnelo Queiroz como ministro e Orlando 
Silva Junior como Secretário-Executivo ${ }^{5}$. A estrutura do Ministério foi composta por três secretarias nos dois mandatos Lula da Silva-PT. A Secretaria Nacional de Esporte de Alto Rendimento lidaria com as políticas concernentes ao esporte profissional e posteriormente com um papel mais central no tocante aos grandes eventos esportivos (Pan-Rio 2007, Copa do Mundo 2014, Jogos Olímpicos- RIO 2016) - ganhando mais vigor no segundo mandato de Lula da Silva. A Secretaria Nacional de Esporte Educacional esteve relacionada com programas que envolvam Esporte e sistema Educacional, preponderantemente o Programa Segundo Tempo. Por fim, a Secretaria Nacional de Desenvolvimento do Esporte e Lazer lidou com programas relacionados ao esporte como lazer e também do financiamento de grupos de pesquisa, eventos científicos, publicações de livros e periódicos. Essa secretaria foi uma espécie de reduto do PT, mais especificamente de seu Setorial de Esporte e Lazer, no âmbito do Ministério, tendo dois titulares durante os governos Lula da Silva/PT: o professor da UNICAMP, Lino Castellani Filho e, a partir de 2006, a ex-secretária de Esportes de Porto Alegre, Rejane Rodrigues.

No primeiro ano de governo, o Ministério do Esporte (ME) apresentou o documento "Uma Política Nacional de Esporte", no qual estabelece que as ações do ME "abrangem todos os tipos de esportes, da recreação à competição, e visam beneficiar todos os brasileiros, em especial, aqueles social e economicamente excluídos" (BRASIL, 2003, P. 1). Neste, o ME saúda o lançamento do documento da ONU-Força-Tarefa (2003) "Esporte para o Desenvolvimento e Paz ...", afirmando ser "... impressionante ver a sintonia que existe entre o que já estamos fazendo aqui no Brasil e o que propõe a ONU" (BRASIL, 2003, p.1). Conforme explicitado em Melo (2011), tal documento representou um passo orgânico rumo à sistematização das proposições do Sistema ONU para o campo do esporte à luz do projeto político burguês para o século XXI.

A declarada influência do documento da ONU- Força Tarefa é traduzida por concepções similares. Como exemplo, a Política Nacional de Esporte de 2003 defende que "um jovem que pratique esporte encontrará mais facilidade de arranjar emprego, pois terá mais disciplina, capacidade de liderança, respeito a regras e noções de trabalho em equipe" (BRASIL, 2003, p. 1). Com uma espécie de alerta às frações burguesas, a Política Nacional afirma que “... um trabalhador que pratique algum esporte ou atividade física terá uma saúde melhor, um humor melhor e, com isso, renderá mais em seu trabalho. Se isso se estender a milhões, o efeito na produtividade do país será rapidamente sentida" (Idid.). Como esse discurso tem como alvo os empresários, fica nítido para quem o Ministério do Esporte começou focando sua atenção.

O documento de 2003 anunciou o Programa Segundo Tempo (PST), o Pro-

5 No início de 2006, Queiroz deixou o Ministério do Esporte para disputar as eleições para o Senado pelo Distrito Federal. Em seu lugar assumiu Silva Junior, que seguiu como Ministro até o fim da gestão Lula da Silva e permaneceu em 2011 no primeiro ano do Governo Dilma Rousseff, tendo saído após uma série de denúncias envolvendo a relação entre o uso de recursos públicos de programas do Ministério por organizações privadas supostamente vinculadas ao PCdoB. 
grama Esporte e Lazer na Cidade (PELC) e iniciou um debate acerca do esporte de alto rendimento. Nesse último caso, já indicava o Programa "Bolsa Atleta", que seria iniciado em 2004, e a aprovação da Lei de Incentivo ao Esporte, permitindo isenção e renúncia fiscal para empresas e/ou pessoas físicas que investissem no esporte. Inclusive faz-se necessário apontar que o PST foi o primeiro programa de intervenção do Ministério a efetivamente entrar em funcionamento, fato diretamente ligado às prioridades político-partidárias, uma vez que o PST era um projeto construído por quadros do PC do B, ao passo que o PELC foi gestado dentro da Secretaria coordenada pelo grupo vinculado ao PT. Como é apontado com detalhes em Melo (2011) é possível afirmar que a execução do PST ao longo do I Mandato- período que esse estudo abarca - guarda profundas relações com os pressupostos do capitalismo neoliberal da terceira via por meio das políticas de parcerias via o chamado terceiro setor. A atuação promotora dos chamados projetos sociais, mesmo tratando-se de políticas governamentais com financiamento e direção político-pedagógica estatal, tem sido a marca dos blocos no poder com afinidade programática ao projeto neoliberal de novo tipo (MELO, 2012).

No início do segundo ano de Governo foi instituída, por meio de Decreto, a realização da I Conferência Nacional do Esporte, na mesma lógica de outras Conferências Nacionais de uma série de temáticas, como saúde, educação etc. Essas conferências contam com a participação de organismos na sociedade civil das diversas classes e grupos sociais e com representantes do bloco no poder. São precedidas por etapas municipais e estaduais, nas quais são debatidos pontos concernentes à Conferência Nacional. O tema da I Conferência Nacional de Esporte foi Esporte, lazer e desenvolvimento humano, tendo sido realizada em junho de 2004, em Brasília.

Como sua configuração será sempre plural, com diversos interesses e projetos societários expressos nas recomendações, a análise do Documento final da I Conferência Nacional de Esporte pode fornecer precisas indicações, tanto dos avanços e retrocessos nesse campo específico, como também apreender os elementos caros ao projeto capitalista neoliberal de Terceira Via presentes no texto final.

Na Carta de Apresentação do documento final da I Conferência, o ex-ministro do Esporte Agnelo Queiroz saúda sua realização e afirma que

\begin{abstract}
este documento tem a finalidade de levar ao conhecimento de todos, comunidade esportiva e a sociedade em geral, o posicionamento e as deliberações que, a partir de agora, passam a orientar e subsidiar a Política Nacional do Esporte e do Lazer já implementada pelo Governo do Presidente Luiz Inácio Lula da Silva, através do Ministério do Esporte (BRASIL, 2004a, p. 1).
\end{abstract}

A sistematização do documento da I Conferência buscou dar um salto de qualidade em relação aos pressupostos apresentados no documento "Uma Política Nacional de Esporte" (BRASIL, 2003). Isso é vislumbrado a partir de uma negativa do papel salvacionista do esporte. Como o tema da Conferência foi "Esporte, lazer e desenvolvimento humano", há a defesa de que o esporte e lazer "contribuem na formação integral das pessoas e na 
melhoria da qualidade de vida do conjunto da sociedade e não devem ser vistos como um instrumento para solucionar ou desviar a atenção dos problemas sociais" (BRASIL, 2004a, p. 2). Apesar disso, posições como essas convivem no mesmo documento com a defesa de que:

No campo do indivíduo e das comunidades, por exemplo, ele [esporte] pode trazer solidariedade, auto-estima, respeito ao próximo, facilidade na comunicação, tolerância, sentido do coletivo, cooperação, disciplina, capacidade de liderança, respeito a regras, noções de trabalho em equipe, vida saudável etc. Também pode auxiliar no combate a doenças, evasão escolar, uso de drogas, criminalidade e entre outras (Idid.).

Nessa linha, a I Conferência (BRASIL, 2004a) ressaltou que “... o Ministério do Esporte colocou em uso a expressão "esporte social", (...) que vem funcionando como uma categoria a mais" (p. 9). Esta classificação indicava a dita preocupação com o que o Ministério do Esporte chamou de inclusão social via esporte.

Os princípios, diretrizes e objetivos de qualquer Conferência Nacional não necessariamente serão implementados pelos Ministérios responsáveis ou outros órgãos estatais. Esses pontos debatidos e presentes nos relatórios finais servem apenas como indicativos de um consenso temporário. Ainda assim, a reiterada posição de que tais pontos orientariam as políticas do esporte e lazer do Ministério do Esporte torna necessária a análise desses elementos.

Nesse sentido, alguns pontos presentes no relatório da I Conferência Nacional de Esporte expressam a contradição de um governo que se arvora no passado de partidos e movimentos sociais que um dia cerraram a fileiras da classe trabalhadora. Tal questão provoca a existência de alguns princípios com elementos que (apenas) sugeriam a possibilidade de apontar para posições contra-hegemônicas. Ao mesmo tempo encontram-se no documento da I Conferência Nacional de Esporte termos caros aos Organismos Internacionais como "vulnerabilidade social", "inclusão social", "gestão participativa". Essa contradição era expressa inclusive na atuação política de intelectuais orgânicos individuais e coletivos com perspectivas absolutamente antagônicas tanto na equipe do Ministério do Esporte, como nas Conferências.

A discussão sobre as propostas de ação, apresentada por eixos temáticos, a partir da I Conferência Nacional de Esporte também merece destaque. No tocante ao "Esporte Educacional", é destacado que os investimentos estatais devem garantir:

... aproveitamento de espaços físicos já existentes nos municípios e estados, com parcerias públicas e privadas que promovam a ampliação da oferta da prática esportiva para alunos e alunas das escolas públicas e comunidade em geral; (...), criação de fundos e incentivos fiscais orientados, principalmente àqueles que desenvolvem programas e projetos sociais e ações interdisciplinares, integradas com outros setores sociais, voltados ao esporte educacional (BRASIL, 2004a, p. 14, grifo nosso).

Essas indicações trazem como proposta da Conferência Nacional, tanto a realização das ditas parcerias público/privadas como também a importância dos incentivos fiscais como mecanismos de obtenção de recursos para as políticas sociais.

Tais elementos são desdobrados na proposição da realização de diagnóstico da 
estrutura esportiva e de lazer, e, sobretudo, na proposição de

....ações articuladas entre os diversos níveis da administração pública e/ou em articulação com a iniciativa privada e organizações da sociedade civil, para construção, modernização, revitalização, preservação, otimização e maximização de espaços e equipamentos para o esporte e lazer com segurança e qualidade, visando o interesse da população (...). Estas ações devem ser promovidas por profissionais, agentes sociais, animadores culturais, voluntários e voluntárias da sociedade capacitados e qualificados (BRASIL, 2004a, p. 17, grifo nosso).

Tanto a premissa das parcerias como a utilização de força de trabalho não paga sob a forma do chamado voluntariado estão presentes como propostas de ações na I Conferência Nacional de Esportes. Isso diz algo acerca da incorporação dos elementos do projeto capitalista neoliberal da Terceira Via nas ações e concepções do Ministério do Esporte. Assim, é possível afirmar que a terceira via busca apresentar pontuais intervenções na dinâmica econômica do projeto neoliberal, e uma busca por ampliar o chamado compromisso social, visando “... conter a explicitação dos antagonismos de classe e administrar os conflitos intra e inter classes em estado latente, em várias partes do mundo, convertendo-os em padrões aceitáveis para a ordem capitalista" (MARTINS, 2009, p. 60).

Como afirma Souza (2011, p. 101), as premissas da I Conferência Nacional contribuíram fortemente para definir "uma "economia política do esporte" na perspectiva do capital. Em acordo com o modo vida/trabalho pautado nas relações capitalistas, constrói esse modelo esportivo ao mesmo tempo em que alimenta e se fortalece, política e economicamente, com essa construção".

Após a I Conferência em 2004, o Ministério do Esporte atualiza o documento "Uma política Nacional para o Esporte", de 2003, dando origem ao texto "Política Nacional do Esporte" (BRASIL, 2005). Um aspecto ressaltado nesse documento é a ação articulada entre Ministério do Esporte e Secretaria Especial dos Direitos Humanos, com vistas a possibilitar "... o financiamento de projetos sociais por meio de incentivo fiscal legal" (BRASIL, 2005, p. 15). Isso implicou que os chamados projetos esportivos sociais possam receber recursos via Fundo Nacional para a Criança e Adolescente (FNCA), a partir da Comissão de Chancela aos Projetos Esportivos Sociais, no interior do Conselho Nacional dos Direitos da Criança e do Adolescente (CONANDA). Essa comissão poderá conferir chancela a programas de esportes para jovens e crianças, desde que registrados no Conselho Municipal de Direitos da Criança e Adolescente da cidade sede. Isso indica que os organismos na sociedade civil ou órgãos estatais contemplados com a chancela possam obter recursos com o que edital chamou de "doadores", que podem ser pessoas físicas ou jurídicas. Esse mecanismo tornou possível que o doador tenha controle exato de qual programa receberá os recursos de sua doação, ao invés de uma doação genérica ao Fundo Nacional da Criança e Adolescente (BRASIL, 2004b).

No sítio do Ministério do Esporte esse elemento ganhou destaque como uma das ações vinculadas à Secretaria Nacional de Esporte Educacional, sob a alcunha de "Projetos Esportivos Sociais". Contando 
com um amplo aparato orientador das ações a serem tomadas pelos demandantes de recursos públicos via mecanismos de contribuição de empresas e/ou pessoas físicas ao Fundo Nacional de Criança e Adolescência, era possível encontrar Manuais de Incentivo Fiscal, orientação para doações, toda legislação concernente a isso, e também os relatos de algumas palestras, bem como os programas que foram contemplados. Como é exposto no sítio do Ministério do Esporte:

Diante de um país em que os problemas sociais são a principal preocupação dos governantes, temos o dever moral e ético de exercermos a Responsabilidade Social, principalmente no que tange à democratização do acesso ao esporte e ao lazer para a infância e a adolescência. (...) Reconhecido sua importância [do esporte e do lazer], esse tema é constante nas discussões entre o Governo Federal e organismos internacionais como a UNESCO, UNICEF e ONU. É sabido que as classes menos favorecidas sempre viram o esporte como uma forma de galgar posições na vida, de superar barreiras da ascensão social e de, potencialmente, obter sucesso. Comprovadamente, na atualidade, sabemos que é muito mais que isso... Fazer e produzir esporte é gerar mais saúde, mais equilíbrio, e é principalmente um importante instrumento para capacitar pessoas a ingressarem construtivamente na sociedade. A Ação Projetos Esportivos Sociais dá oportunidade para ampliarmos o atendimento da demanda sócio-esportiva do país, firmando novas parcerias com os mais diversos setores, que engajados visam contribuir efetivamente para o combate das mazelas de nossa sociedade, e que consequentemente irão agregar valores inestimáveis às suas marcas, $\mathrm{e}$ inerentes a essa Ação, como: Responsabilidade Social, Sustentabilidade e Governança (Ministério do Esporte, 2011, s.p., grifos nossos).
O trecho em destaque retoma um discurso que apresenta uma concepção mistificada das possibilidades ou potencialidades da prática esportiva, fato que nos remete a seguinte questão: qual é a manifestação esportiva desenvolvida nesses programas e que parametriza suas ações? Não obstante, a adoção e a materialização de ações concretas com bases nos pressupostos emanados do projeto neoliberal e de seus principais intelectuais orgânicos, como mostra Melo (2012).

O mecanismo, apresentado pelo Ministério do Esporte como possibilidade de financiar as políticas (estatais) e programas (privados) de esportes para jovens e crianças, representa um passo adiante na privatização dessas políticas. Diante da organização proposta, o chamado doador passa a ter uma relação direta com o público atendido nesses programas. No caso de uma doação vultosa poderá até mesmo ser o único doador de um programa, o que lhe conferirá uma significativa exposição de sua marca, o que contribui para se materializar como um excelente mecanismo de obtenção do consenso.

A adoção da responsabilidade social por parte do Governo Lula da Silva/ PT confirma o postulado de Martins (2009) de que sequer houve um enfrentamento pedagógico dessa concepção tão cara à dominação burguesa. Dentre os objetivos específicos desse programa "Projetos Esportivos- sociais" estavam apontados "Possibilitar que o esporte seja o ponto de partida para a ascensão social, através da descoberta e aproveitamento de talentos; Agregar conceitos de Responsabilidade Social aos agentes envolvidos no Projeto" (BRASIL, 2011, s.p). 
Há uma defesa da necessidade de diversificar e dinamizar as fontes para os programas e projetos de esportes no Brasil. Segundo o Ministério do Esporte (2011; 2004b), as fontes para financiar essas políticas são o orçamento da união, recursos específicos para Formação Esportiva, recursos oriundos da Lei Agnelo/Piva, da Bolsa Atleta, da Loteria Time-Mania e do patrocínio esportivos por Empresas Estatais (Petrobras, Eletrobrás, CAIXA, Correios etc). Além destes, também destacados outras fontes como as "... constituídas por parcerias com empresas na busca de captação de recursos, com incentivo fiscal pelo CONANDA, através do Fundo de Incentivo a Projetos Esportivos Sociais" (2004b, p. 21).

A partir disso, a Política Nacional do Esporte cita os dois programas de implementação do Ministério do Esporte. Esses são o Programa Esporte e Lazer na Cidade (PELC) e o Programa Segundo Tempo (PST), inclusive salientando que tais iniciativas foram reconhecidas pela $\mathrm{ONU}$, implicando em destaque internacional ao país.

Por fim, a Política Nacional de Esporte (BRASIL, 2003, p. 37-39) delineia o que chamou de diretrizes para suas ações. Esses oito itens são: 1) universalização do acesso e promoção da inclusão social; 2) desenvolvimento humano; 3) ciência e tecnologia do esporte; 4) promoção da saúde; 5) paz e desenvolvimento da nação; 6) Desenvolvimento econômico; 7) Gestão Democrática: participação e controle social; 8) Descentralização da política esportiva e de lazer.

Algumas dessas diretrizes, ao serem desdobradas, apresentam inequívocas vinculações com os pressupostos do projeto neoliberal da Terceira Via. Por exemplo, a diretriz 5, "Paz e Desenvolvimento da Nação", é iniciada com a defesa da

capacidade de mobilização social das causas e dos eventos esportivos pode e deve ser direcionada para o desenvolvimento social, estimulando o alcance da coesão e da estabilidade, inclusive por meio de ações voluntárias. Os programas de esporte devem valorizar a autoestima, visando o fortalecimento do espírito patriótico e da identidade nacional, reforçando os princípios necessários para o desenvolvimento da nação e da paz (BRASIL, 2003, p. 38).

Em 2006 o Ministério do Esporte promoveu a II Conferência Nacional de Esporte com a intenção de debater a construção do Sistema Nacional de Esporte e Lazer, sendo este o tema dessa Conferência. A composição desse Sistema Nacional buscava abarcar a totalidade de ações e sujeitos políticos no campo esportivo e do lazer.

A constituição do Sistema Nacional de Esporte e Lazer implicaria numa capacidade de planejamento, normatização e fiscalização por parte do Ministério como forma de garantir o cumprimento dos elementos. Efetivamente, quer dizer que a atuação de órgãos federais, estaduais, municipais, organismos na sociedade civil no âmbito do esporte e lazer deveriam ser regidos com base nos pressupostos e normatizações do Sistema Nacional de Esporte e Lazer, inclusive com a aprovação de uma Lei Orgânica ou lei de diretrizes e bases do esporte nacional.

Como afirma Souza (2011, p. 110)

O Sistema Nacional de Esporte e Lazer, apesar de se apresentar de forma mais detalhada, é simplesmente um ordenamento do que já existia, o que revela 
que a institucionalização do fenômeno esportivo por meio do Sistema Nacional de Esporte continua sendo uma proposta inócua e abstrata para se realizar grande parte dos anúncios proferidos, até mesmo, pelo bloco no poder durante todo esse período de Conferências.

O Sistema Nacional de Esporte e Lazer é concebido a partir do regime de colaboração entre a União, os estados e municípios, enfatizando a municipalização. Tal sistema deveria promover a articulação, a integração, a promoção e o estabelecimento do que chama de relações éticas de parcerias entre os organismos na sociedade civil, órgãos da aparelhagem estatal. Não por acaso, é conferida a atribuição aos órgãos estaduais e municipais de gestão das políticas de esporte e lazer de “... promover a articulação entre as escolas públicas e particulares e comunidades com intuito de abranger várias classes sociais, junto às ligas, associações e federações escolares ou não, sempre que possível, ONGs e OSCIPs ligadas ao segmento" (BRASIL, 2006a, p. 1). Junto a isso, também é apontado caber a tais órgãos a criação de "um banco de dados de voluntariado desde que cada um respeite sua formação e habilitação e restringindo sua ação a dar apoio nos eventos" (BRASIL, 2006a p. 2).

O fato de aparecerem como propostas aprovadas na II Conferência Nacional de Esporte é um indicativo de que se tornou lugar comum tanto a presença do chamado terceiro setor, quanto da possibilidade de utilização de força de trabalho não paga mediante o voluntariado. Assim, é sem surpresa que outra proposta aprovada na II Conferência aprofunde esses princípios. A proposta versou sobre:
... o estabelecimento de parcerias técnicas e financeiras, convênios, consórcios e cooperações entre as três esferas governamentais, com a iniciativa privada e com o terceiro setor, a fim de viabilizar ações que estimulem e promovam o esporte e o lazer. Tais parcerias, convênios e cooperações deverão apontar para políticas intersetoriais (...) (BRASIL, 2006a p. 7).

Se as propostas aprovadas não podem ser atribuídas diretamente como concepções geradas a partir do Ministério do Esporte, os chamados "Textos Básicos para as Etapas da II Conferência" (BRASIL, 2006b) certamente podem ser considerados como tal. É importante ver que esses textos bases indicavam uma busca do Ministério do Esporte por dar uma direção ao debate a partir de seus pressupostos e concepções de mundo.

E um desses textos, ao analisar o Eixo 3, "Gestão e Controle Social", o Ministério do Esporte toma uma posição que é deveras emblemática de sua filiação as teses do neoliberalismo de Terceira Via. Após apontar a necessidade de pensar o Sistema Nacional de Esporte e Lazer como um todo, e proclamando a necessidade de universalização do acesso ao esporte e lazer no país, o Ministério do Esporte afirma que isso não implicaria em considerar apenas a ação estatal. Mais especificamente, defende que "em que pese o dever do Estado de fomentar o esporte e o lazer, o sistema deve contemplar outras iniciativas e parcerias, inclusive financeira, para sua viabilização" (BRASIL, 2006b, p. 11). Tal posição é complementada com defesa da dita diversificação das

...fontes de financiamento para além dos recursos oriundos dos orçamentos 
da União, uma vez que não se deve incorrer numa visão paternalista em que toda a responsabilidade de prover a viabilização do esporte e do lazer seja do estado, embora esse seja um dever constitucional, suas possibilidades poderão não satisfazer a universalização, amplitude democrática e diversificação na participação que se pretende empreender com a criação do Sistema Nacional. Essa responsabilidade deve ser co-partilhada com um conjunto de instituições, entidades públicas e privadas com redes de cooperação, parcerias e outros meios que devem ser elencados para o debate (BRASIL, 2006b, p. 14, grifo nosso).

Também há um apelo pela mobilização do chamado apoio privado “... para desenvolver o esporte nacional, o que requer, numa fase de transição, a concessão de benefícios fiscais aos investidores, contribuindo para a formação de uma nova cultura no meio empresarial" (BRASIL, 2006b, p. 25).

A prática de isenção fiscal a "investidores" estrangeiros não é um expediente extraordinário na história brasileira - lanni (1994) observou esse exercício como um dos elementos de intervenção estatal da década de 1950 na tentativa de dinamizar o desenvolvimento econômico. O referido expediente também não é inaudito em se tratando de Governo Lula. Salvador (2010) relembra que, por meio da edição da MP $n^{\circ}$. 281/2006, o referido governo reduziu a zero a alíquota de IR e CPMF para esse mesmo grupo. Como as operações beneficiadas por esta MP são cotas de fundos de investimentos exclusivos para investidores externos que possuam no mínimo 98\% de títulos públicos brasileiros, o autor conclui que essa benevolência tributária beneficiou majoritariamente aos banqueiros.
Como aponta Souza (2011), na II Conferência Nacional de Esporte aprovou-se a proposta que subsidiou a lei regulamentadora de incentivos fiscais para os esportes. Essa lei (11.438/2006), sancionada em 29 de dezembro de 2006, permite a dedução fiscal tanto de pessoa física como jurídica mediante doações e/ou patrocínios para programas esportivos de diversos tipos, ainda que os projetos precisem ser aprovados previamente pelo Ministério do Esporte. É necessário destacarmos que a política de isenção fiscal - por trás dos estímulos às doações financeiras e da noção de "responsabilidade social" - é mais um dos mecanismos de assalto ao fundo público.

\section{CONCLUSÃO}

Como afirmam Filgueiras e Gonçalves (2007), Fontes (2005), Oliveira (2006) a alegada mudança de posição de PT com a chegada de Lula da Silva ao poder central longe de ser explicada como apenas traição, demanda ser aprofundada para a compreensão de uma série de elementos que compõem esse processo. O que é inequívoco é que se trata de uma das maiores derrotas das forças populares no Brasil.

Especificamente no campo das políticas de esportes é possível vislumbrar uma característica de transformar as ditas parceiras em mecanismo de atuação estatal. Assim, as expressões da direita para o social (MARTINS, 2009) deram amplos passos no âmbito do I mandato do Governo Lula da Silva-PT nas políticas de esportes. Tem sido ponto central da estruturação da ação em diversos campos, tal elemento caríssimo ao projeto neoliberal de terceira via teve desdobramentos concretos nas ações 
implementadas. As posições assumidas nos documentos, que indicam ações concretas, expressam justamente essa aproximação inconteste. Isso confere mais precisão à afirmação de Melo (2012) de que as políticas de esportes são parte da contraditória luta dos trabalhadores no bojo do capitalismo na garantia desse direito social.

Nesse contexto já aludido de um novo papel político e um modus operandi do Estado e das organizações na sociedade civil na oferta das políticas sociais, a Terceira Via busca educar politicamente os trabalhadores para uma "... nova dinâmica social em que o Estado de 'protetor', seria o indutor do 'progresso' e cada um, de receptor dos bens sociais e culturais, tornar-se-ia o empreendedor de seu sucesso (ou fracasso), a partir da liberdade de escolhas e autonomia para agir" (MARTINS, 2009, p. 84). Para tal são fundamentais as organizações na sociedade civil - sobretudo àquelas com algum vínculo com as frações mais exploradas da classe trabalhadora atuarem nos níveis mais elementares de consciência política, sem buscar aprofundar o entendimento da realidade sócio-histórico a partir de sua própria atuação política. Isso inclui formar uma nova geração tanto de crianças como de adultos nos chamados programas e projetos sociais, em que as noções de empreendedorismo, voluntariado e responsabilidade social sejam concebidas como orientadores das sociabilidades e de suas visões de mundo acerca de uma série de questões. A repolitização da política se completa com esse espraiamento medular e intermitente desses elementos na vida social dos setores mais explorados. Juntamente aos programas de renda Mínima - até para reafirmar a posição acerca da base material da dominação capitalista, que precisa ir além do engodo e do encobrimento da realidade - o programa da Terceira Via consegue atualizar a agenda de dominação do capital, ampliando a base de sustentação política com os próprios explorados.

\section{REFERÊNCIAS}

BEHRING, Elaine \& BOSCHETI, Ivonete. Política Social: fundamentos e história. $3^{\mathrm{a}}$ Ed. São Paulo: Cortez Editora, 2007. BOITO JUNIOR, Armando. A burguesia no Governo Lula. Crítica Marxista. № 21, Rio de Janeiro, p. 52-76, 2005.

BRASIL. Ministério do Esporte. Política

Nacional de Esporte. Brasília: Ministério do Esporte: 2005.

BRASIL. Ministério do Esporte. Documento Final da I Conferência Nacional de Esporte. Brasília: Ministério do Esporte, 2004a.

BRASIL. Ministério do Esporte. Conselho Nacional dos Direitos da Criança e do Adolescente. Edital para Inscrição de projetos esportivos-sociais. Brasília: Ministério do Esporte, 2004b. Disponível em: < http://portal.esporte. gov.br/snee/esportesocial/ $>$. Acesso em: 24 jul. 2005.

BRASIL. Ministério do Esporte. Projetos Esportivos-sociais. Brasília: Ministério do Esporte, 2011. Disponível em: $<$ http://www.esporte. gov.br/snee/ esportesocial/default.jsp > . Acesso em: 20 maio 2011.

BRASIL. Ministério do Esporte. Resoluções da II Conferência Nacional do Esporte. Brasília: Ministério do Esporte, 2006a. BRASIL. Ministério do Esporte. Coletânea de Textos: Textos Básicos para as Etapas da Il Conferência. Brasília: Ministério do Esporte, 2006b. 
BRASIL. Ministério do Esporte. Uma Política Nacional de Esporte. Disponível em: <www.esporte.gov.br. 2003>. Acesso em: 20 out. 2003.

CAVALCANTI, Luiz Otávio. O que é o governo Lula? São Paulo: Landy Editora, 2003.

CHESNAIS, François, et al. Uma nova fase do capitalismo? São Paulo: Xamã, 2003.

CICHON, Michael; BEHRENDT, Christina \& WOSDAK, Veronica. La iniciativa dele Piso de Protecional Social de lãs Aciones Unidas. Alemaniza: FriedrichEbert-Tse-tung. 2011.

COELHO, Eurelino. Uma esquerda para o Capital: o transformismo dos Grupos Dirigentes do PT (1979-1998). São Paulo: Feira de Santana: Xamã Editora/ Editora da UEFS, 2012.

COUTINHO, Carlos Nelson. Intervenções: o marxismo na batalha das ideias. São Paulo: Cortez, 2006.

FAGNANI, Eduardo. Piso de Proteção Social: o debate internacional e a experiência brasileira. Texto para Discussão. IE/Unicamp, Campinas, n. 203, abr. 2012.

FILGUEIRAS Luiz, GONÇALVES, Reinaldo. A economia política do Governo Lula. Rio de Janeiro: Editora Contraponto, 2007.

FONTES, Virgínia. Reflexões Im-pertinentes:

História e capitalismo contemporâneo. Rio de Janeiro: Bom texto, 2005.

HARVEY, David. O Neoliberalismo: história e implicações. São Paulo: Edições Loyola, 2008.

IANNI, Otávio. O colapso do populismo no Brasil. 5. ed. Rio de Janeiro: Civilização Brasileira, 1994.

LULA DA SILVA, Luiz Inácio. Carta ao Povo Brasileiro. 2002. Disponível em: < http:// www2.fpa.org.br/portal/modules/news/ article.php?storyid $=2324>$. Acesso em: 05 jan. 2007.

MARQUES, Rosa \& MENDES, Áquila. O Social no Governo Lula: a construção de um novo populismo em tempos de aplicação de uma agenda neoliberal. Revista de Economia Política, São Paulo, VOL 26, no 1 (101), pp. 58-74, Jan/Mar de 2006.

MARTINS, André Silva. A direita para o social: a educação da sociabilidade no Brasil contemporâneo. Juiz de Fora: Editora UFJF, 2009.

MELO, Marcelo Paula de. Políticas Sociais de Esporte e Lazer, Sociedade Civil e Teoria de Estado: a defesa da radicalidade gramsciana. Motrivivência, Vol.2, Ano, XXIV (38), p. 59-74. 2012

. Esporte e dominação burguesa no século XXI: a agenda dos Organismos Internacionais e sua incidência nas políticas de esportes no Brasil de hoje. Tese (Doutorado em Serviço Social). Rio de Janeiro: Universidade Federal do Rio de Janeiro: 2011.

OLIVEIRA, Francisco. O Momento Lênin. Novos Estudos CEBRAP, São Paulo, no 75, p.23-47, JUL/06. 2006.

ONU. Força Tarefa Inter-Agências da ONU. Esporte para o desenvolvimento e paz: em direção à realização das metas de desenvolvimento do milênio. Nova Iorque; Nações Unidas; 2003.

PAULANI, Leda. O projeto neoliberal para a sociedade brasileira: sua dinâmica e seus impasses. In: Lima, Julio César \&, Neves, Lúcia Maria. (orgs). Fundamentos da educação escolar do Brasil contemporâneo. Rio de Janeiro: Fiocruz, 2006. p. 67-108.

PEREIRA-PEREIRA, Potyara. Utopias desenvolvimentistas e política social 
no Brasil. Revista Serviço Social e

Sociedade, São Paulo, n. 112, p. 729-

753, out./dez. 2012.

SALVADOR, Evilásio. Fundo público e seguridade social no Brasil. São Paulo:

Cortez, 2010.
SOUZA, Carlos Eduardo. A Política Nacional de Esporte no Brasil Contemporâneo como Estratégia para educar o consenso. Dissertação (Mestrado em Educação). Juiz de Fora: Universidade Federal de Juiz de Fora, 2011.

\title{
I MANDATE GOVERNMENT LULA DA SILVA / PT (2003-2006) AND SPORTS POLICIES: deepening the neoliberal project
}

\begin{abstract}
He aim of this paper is to discuss the actions of the Ministry of Sports in I Mandate Government Lula da Silva / PT (2003-2006). This time frame is justified by this mandate have been considered as a moment of internal disputes about the government's direction and expectations of the PT in power could represent a coping perspective of Brazilian bourgeois logic. We will show that these expectations have not been realized and that the programmatic adherence to the neoliberal project was present in programs and pronouncements of its leaders. The incorporation of actions based on social responsibility, protecting the performance of organizations in civil society through partnerships policies and defending the tax exemption for public resource transfers to such entities, the voluntary use of proposal authorizes such claims.
\end{abstract}

Keywords: Ministry, Sports, Lula da Silva, PT; Neoliberalism

\section{MANDATO DEL GOBIERNO LULA DA SILVA / PT (2003-2006) Y DEPORTIVAS POLÍTICAS: la profundización del proyecto neoliberal}

\section{RESUMEN}

El objetivo de este trabajo es discutir las acciones del Ministerio de Deportes en la Primera mandato del gobierno Lula da Silva Este / Pacífico (2003-2006). Este período de tiempo se justifica por este mandato se han considerado como un momento de disputas internas sobre la dirección y las expectativas del PT en el poder podría representar una perspectiva de afrontamiento de la lógica burguesa brasileña del gobierno. Vamos a demostrar que estas expectativas no se han cumplido y que la adhesión programación al proyecto neoliberal estaba presente en los programas y las declaraciones de sus líderes. La incorporación de acciones basadas en la responsabilidad social, la protección de la actuación de las organizaciones de la sociedad civil a través de las políticas de alianzas y defienden la exención fiscal de las transferencias de recursos públicos a dichas entidades, el uso voluntario de la propuesta autoriza a dichas reclamaciones.

Palabras clave: Ministerio, Deportes, Lula da Silva, PT, Neoliberalismo 